\title{
Just Say No (For Now): The Ethics of Illegal Drug Use ${ }^{1}$
}

\author{
MATHIEU DOUCET \\ University of Waterloo
}

\begin{abstract}
The war on drugs is widely criticized as unjust. The idea that the laws prohibiting drugs are unjust can easily lead to the conclusion that those laws do not deserve our respect, so that our only moral reason to obey them flows from a general moral obligation to obey the law, rather than from anything morally troubling about drug use itself.

In this paper, I argue that this line of thinking is mistaken. I begin by arguing that the drug laws are indeed unjust. However, so long as they remain prohibited, I argue that we have strong moral reasons to avoid drug use. First, drug users are partly responsible for the violent and exploitative conditions in which many drugs are produced and distributed. Second, the unequal ways in which drug laws are enforced make drug use by many an unethical exercise of privilege. These reasons do not depend on the existence of a general moral obligation to obey the law; we ought to refrain from illegal drug use even if prohibition is unjust and even if we have no general obligation to obey the law. In fact, drug laws turn out to represent an interesting exception case within the broader debate about this obligation, and I argue that it is the very injustice of the law that generates the reasons not to violate it.
\end{abstract}

Keywords: war on drugs, obligation, drugs, consumer ethics

\section{INTRODUCTION}

Is it unethical to use illegal drugs? According to one way of thinking about this question, the answer depends on our views about the ethics of obedience to the law. We might think drug use is unethical because it is

1 Thanks to Lisa Farlow, the audience at the 2014 Canadian Philosophical Association meetings at Brock University, and an anonymous reviewer for this journal for helpful comments on previous versions of this paper. 
illegal, on the grounds that it is (typically) unethical to break the laws of a just state. On the other hand, we might think that drug prohibition is unjust, and therefore does not command our obedience.

There is, however, another way of thinking about the question. Rather than focusing on the ethics of drug use through the lens of the law, we might think instead of recreational drugs as popular consumer products. Considered in this way, we can ask whether the purchase and consumption of illegal drugs is unethical, in much the same way we can ask whether it is ethical to purchase any other consumer product. Many consumer goods are produced in harmful, exploitative, or environmentally damaging ways, and this raises important moral worries for consumers. The 2013 Rana Plaza garment factory collapse in Bangladesh, for instance, brought the ethics of low-cost clothing into public consciousness; animal welfare activists have long argued that factory-farmed meat is unethical; and the environmental costs of gas-powered SUVs, for example, make them targets of moral critique.

This way of asking about the ethics of drug use does not presume that the most important element in the answer is their legal status. Nonetheless, I argue that, considered simply as consumer products, we have strong moral reasons to refrain from the use of recreational drugs so long as they remain illegal. This is not because we have strong moral reasons not to break the law, but rather because drug prohibition contributes in an important way to the conditions that do make the purchase and use of recreational drugs unethical.

Section 2 argues that drug prohibition is unjust. For some, this means that the drug laws do not deserve our respect, and so drug use is not a significant moral issue. However, section 3 goes on to argue that so long as drugs remain illegal, there are strong moral reasons to avoid using them. This is for two distinct reasons. First, drug users are partly responsible for the violent and exploitative conditions in which many drugs are produced and distributed. Second, the unequal ways in which drug laws are enforced make use by many into an unethical exercise of privilege.

The fact that drugs are legally prohibited plays an important role in this argument, since the harmful conditions of production and distribution and the unequal enforcement are both generated by prohibition. However, the argument does not depend on the existence of a general moral obligation to obey the law: Section 4 argues that we ought to refrain from illegal drug use even if prohibition is unjust and even if we have no general moral obligation to obey the laws of a just state. In fact, drug laws turn out to represent an interesting exception case within the broader debate about this obligation. Regardless of whether we have such an obligation, we have 
strong moral reasons not to violate drug laws. Finally, Section 5 considers a range of potential objections to the argument.

Paradoxically, the very reasons that make drug laws unjust also give us strong moral reasons not to use illegal drugs. Our strong moral reasons to avoid drugs arise not in spite of the injustice of the drug laws, but rather precisely because of those laws; in the absence of prohibition, drug use would be, at the very least, much less immoral (and perhaps not immoral at all). This gives us a reason both to avoid drugs while they are illegal, and to seek to overturn the prohibition of drugs, whether or not we wish to use them.

\section{THE INJUSTICE OF PROHIBITION}

There are many arguments that drug prohibition is unjust. Some claim that drug use is a 'victimless crime', and so prohibition interferes with liberty. Others point to the hypocrisy of governments banning most drugs out of a professed concern for health while permitting - and profiting from - the sale of alcohol and tobacco. While drugs can be very unhealthy, so too are many things that governments do not control with criminal sanctions (Husak 2002, 2005). These arguments are powerful, but they are not my main focus. ${ }^{2}$ Even if we set aside concerns about liberty and hypocrisy, existing drug laws are unjust because of the considerable harms they generate.

Drug prohibition is often justified on the grounds that drugs are harmful to users' health. Drug use can indeed cause significant harms, including death, and one powerful idea supporting prohibition is that it reduces overall rates of drug use, and so protects potential drug users from serious harm. However, proponents of the 'harm reduction' approach to drugs often point out that prohibition can exacerbate the health problems it is intended to address. Prohibition does not put an end to drug use; in fact, the evidence from Europe suggests that it does not even effectively reduce drug use, since decriminalization does not contribute to an increase in drug use (Vuolo 2013). What prohibition does do is marginalize drug users, making them more vulnerable and less able to access health care and other social services. It can therefore increase the negative health impacts of drug use, even when rates of drug use decline (Drucker 1999). Advocates of harm reduction therefore frequently advocate for decriminalization in order to reduce the health impacts of drug use. If the justification for

2 Two potential objections are that: 1) some liberties can be justifiably restricted to achieve important social goods, and drug prohibition may be an example of such a justified restriction; and 2) inconsistencies can be resolved in more than one way. Perhaps the real problem is the legal status of alcohol, not the prohibition of other drugs. 
prohibition is that it protects health, and if, as the evidence seems to suggest, it actually contributes to worse overall health outcomes, then prohibition, with all of its attendant costs, is unjustified.

These costs are significant, and affect many more people than drug users. In fact, these costs are so significant that there are good reasons to think that prohibition would be unjustified even if it did succeed it its aim of protecting the health of potential drug users.

First, prohibition creates an illegal black market for the production and distribution of drugs, and this black market is remarkably violent. Between 2006 and 2010, for example, the war between drug cartels and the Mexican government killed at least 41,648 people and perhaps tens of thousands more. ${ }^{3}$ Much of this violence is a direct result of existing drug laws. The trade is not governed by contracts, disputes cannot be dealt with in the courts, and because it is illegal the drug trade is (for some) incredibly profitable. These facts combine to incentivize violence. Repealing drug laws and ending the War on Drugs might not completely eliminate drugrelated violence, since even legal markets can attract violence. Nonetheless, the evidence strongly suggests that prohibition significantly increases that violence (Werb et al. 2010).

Second, violent crime is not the only social cost of the drug trade. Those who work in the drug trade are workers: they are employed in a large and profitable economic sector. Because it is illegal, those workers face the risk of violence without protection from contract law, labor law, employment insurance, or workers' compensation. They are therefore open to serious exploitation, and are generally poorly paid: American drug dealers often earn less than minimum wage in a very dangerous occupation (Levitt and Venkatesh 2000). If the exploitation of Bangladeshi garment workers gives us pause, the exploitation of Mexican and North American drug workers made possible by prohibition should as well.

Third, drug workers and users face significant risks of incarceration, which, even more than drug-related violence, is the direct result of prohibition. In 2015, there were close to 300,000 people incarcerated in American for drug crimes (Carson and Anderson 2016), and another 947,000 on probation (Kaeble and Bonczar 2016), for a total of more than 1.2 million Americans with their autonomy significantly restricted because of

3 For the lower estimate, see (Rios 2013). For a discussion of the criticisms of this estimate, see (Cave 2012). 
drug prohibition. ${ }^{4}$ Since this number excludes most drug-related violent crime, it likely under-reports the number of people incarcerated because of drug prohibition. Moreover, incarceration does not just impose a cost on drug offenders: it is costly to the state, since housing so many prisoners is extremely expensive. Government money spent on the drug war is money that cannot be spend on other valuable government programs, and such opportunity costs should be counted among the real costs of the drug war. If the drug laws are not justified, then many of these costs are not justified either.

Fourth, those convicted of drug crimes suffer real harms in addition to incarceration. In many jurisdictions, released felons lose voting rights and the right to sit on juries. They also lose access to public housing, federal student loans, federal health and welfare programs, and food stamps (Alexander 2010: Ch. 4). If they were employed, they typically lose their jobs, and face reduced economic opportunities upon their release, as employers can deny jobs to those convicted of a crime.

Finally, drug laws are enforced in an unjust way. Despite roughly similar rates of drug use, African-Americans are arrested for drug crimes at a much higher rate than whites, a difference that cannot be explained by the differing nature of drug offending between races (Mitchell and Caudy 2015). For example, African-Americans make up $13.3 \%$ of the US population, but $38.3 \%$ of those in federal prison on drug changes; white (non-Hispanic) Americans, by contrast, are $62 \%$ of the US population but only $21.6 \%$ of those in federal prison on drug charges (Taxy et al. 2015). This means that African Americans are nine times as likely as white Americans to be in federal prison on drug convictions. The injustice of the racial disparity in drug law enforcement compounds the social costs of incarceration. It is not merely that drug offenders are imprisoned, lose their political rights, and suffer economic and social dislocation, though these are serious costs. It is also that these costs are born disproportionately by already disadvantaged racial minorities. This has led Michelle Alexander, among others, to compare drug laws to the Jim Crow laws, which were used to deny African-Americans housing, jobs, and democratic rights (2010). The racial disparity in enforcement makes African-American communities poorer, more vulnerable, and less politically influential. Drug laws therefore play an important role in

4 The 298,704 people in state and federal prisons on drug charges in 2015 represented a relatively small percentage - under $20 \%$ - of those incarcerated in America (Carson and Anderson 2016), and so as John Pfaff points out (2017), drug prohibition cannot explain the phenomenon of mass incarceration. Nevertheless, the overall American incarceration rate is so high that the drug crime incarceration rate is higher than the total incarceration rate in many countries, including Germany and Canada (Wagner and Walsh 2016). 
perpetuating the systematic racism in American society.

All told, then, drug laws carry enormous social costs. If these costs are to be justified, they should be outweighed by corresponding social benefits. While the exact effect of prohibition on the rate of drug use and the health-related harms of drugs is a complex question, those who aim to reduce the health costs of drug use frequently argue in favor of decriminalization or legalization rather than prohibition. But even if this is a mistake, and it turns out that prohibition does reduce the rate of use and the health-related harms of drugs, these benefits need to be balanced against the other enormous costs associated with prohibition. Those costs - including violence, worker exploitation, mass incarceration, community dislocation, and systematic racism - significantly outweigh whatever marginal reduction in drug use or health costs might be gained by prohibition. As a result, the legal prohibition of drugs is unjust.

\section{MORAL REASONS TO AVOID ILLEGAL DRUGS}

I've argued that drug prohibition is unjust. But what are the moral implications, for individuals, of this claim? The most obvious one is that we ought to work to repeal prohibition, including pressuring our political representatives to abandon the War on Drugs. Some jurisdictions have taken steps in that direction. In 2001, Portugal decriminalized simple possession of all drugs: drug users are directed to treatment, and punished with, at most, a small fine. Drug dealing, however, dealing remains criminalized. Recreational use of marijuana is legal in Uruguay, in eight American states and the District of Columbia, and the government of Canada has committed to the legalization of marijuana by July of 2018 . At present, however, the wholesale legalization of drugs is politically unfeasible in almost every country. Given the injustice of those laws, it is tempting to suppose that they simply do not have any claim on our respect, and so that drug use is not particularly morally objectionable.

There are certainly perfectly good non-moral reasons not to take drugs. First, many illegal drugs carry serious health risks. These risks may not be a good reason to outlaw drugs - in fact, they may be a good reason not to outlaw drugs - but they can be a very good reason not to take drugs. Second, given the drugs are illegal, in buying and using drugs one runs the risk of criminal sanction, including prison. As we saw, this is a non-negligible risk for members of underprivileged groups. However, both of these reasons are prudential. It may be in our self-interest to avoid illegal drugs, but do we have a moral reason to refrain from purchasing and consuming them? 
I argue that illegal drug use is indeed immoral. The prohibition of drugs is certainly unjust. Nonetheless, the current prohibition drugs gives us two distinct moral reasons to not violate drug law. First, drugs are produced and distributed in ways that are unethical. Second, the use of drugs by many consumers represents an objectionable form of privilege. Moreover, we have these moral reasons to avoid drugs, not merely in spite of the law's injustice, but rather because of it. Paradoxically, it seems, it is precisely the injustice of the laws banning drugs that makes violating those laws immoral.

\subsection{Unethical production}

The harm reduction approach to drugs endorses treating them much like other dangerous consumer products. This is an argument for repealing prohibition, but thinking of drugs as consumer products has other moral implications. After all, we have strong moral reasons to avoid consumer products that are produced in unnecessarily dangerous and exploitative ways. For example, we ought to avoid purchasing clothing that is made is dangerous sweatshops or by child labor. Ethically produced clothing might be more expensive, but cost savings for relatively affluent consumers do not justify the exploitation and deaths of Bangladeshi garment workers.

The drug trade, as we saw, is violent and exploitative: drug workers are killed and exploited in significant numbers. We ought therefore to avoid drugs for the same reason that we ought not to buy clothing made in dangerous sweatshops; both are produced in dangerous and exploitative ways, and consumers both enable and benefit from that exploitation. The point it is not merely that we could do something to prevent the harms of the drug trade, though this is certainly true. Rather, the point is that drug users are in an important sense directly responsible for those harms. It is their demand for drugs that allows the harms of the drug trade to persist. Drug users are not, of course, solely responsible for those harms, since governments who enforce prohibition share in the blame. Nonetheless, given the reality of prohibition, drug users are blameworthy for the harms that their consumption choices help to bring about. The many affluent North Americans and Europeans who insist on purchasing ethically produced, organic, and fair-trade consumer goods should also avoid illegal drugs, since the reasons we have to avoid such drugs are of a piece with the more general moral reason we have to avoid all unethically produced products.

However, these moral reasons to avoid illegal drugs are arguably stronger than they are for most unethical consumer goods. First, compared to other unethically produced goods, the drug trade combines significantly 
greater harms with significantly fewer consumers. Almost everyone in North America and Western Europe wears clothing every day. The majority likely own some clothing produced in an unsafe and exploitative sweatshop. By contrast, around half of North Americans have never used illegal drugs, ${ }^{5}$ and under $10 \%$ use them regularly. ${ }^{6}$ Nonetheless, despite the much smaller size of the illegal drug market, drug-related violence kills many more people than die in unsafe garment factories. The collapse of the Rana Plaza in April 2013 killed 1,129 Bangladeshis, mostly garment workers, and a factory fire in 2012 killed another 117. These numbers are alarming, but they pale in comparison to the thousands of Americans and tens of thousands of Mexicans killed in drug violence since 2006. This is not to minimize the harms of the garment industry, but instead to highlight the enormous harms caused by the drug war. To the extent that those who buy drugs or unethically produced clothing are implicated in the harms associated with their production, those who buy drugs are much more implicated, since the far greater harms are spread across a much smaller number of customers.

Second, there are institutional differences between the harms resulting from the drug trade and from unethical garment factories. The harms of the drug trade are a direct product of the criminal laws: it is because drugs are illegal that there is so much violence and exploitation in their production and distribution. The harms of the garment industry, by contrast, emerge in large part from a global economic system in which multinational corporations seek to maximize profits by manufacturing goods in countries that have low labor costs, and correspondingly low labor standards and protections.

This is an important difference, since the criminal law is under democratic control in ways that global economic institutions are not. Americans cannot simply end prohibition by voting for a party that promises to do so; there is no such party and in any case American (and other) democratic institutions are structured so that majority public

5 In 2015, 50\% of Americans over the age of 25 reported using illicit drugs at least once in their lives. By far the most commonly used drug is cannabis, with $46 \%$ reporting lifetime use. Cocaine and hallucinogens, both at $16 \%$, were next on the list of lifetime prevalence. Only $2 \%$ have ever tried heroin (NIDA 2015a). Canadian numbers are similar: in 2012, $43 \%$ of Canadians reported lifetime use of cannabis, though that number drops to $34.7 \%$ when one-time users are excluded (Rotermann and Langlois 2015). Numbers from Mexico are less reliable, but a 2008 WHO survey put lifetime cannabis use by Mexicans at $7.8 \%$, and lifetime use of cocaine at $4 \%$ (Degenhardt et al. 2008).

6 In 2015, 13\% of Canadians reported using illegal drugs in the previous year, a number that falls to $2 \%$ when marijuana is excluded. (Health Canada 2015). In 2013, $9.4 \%$ of Americans reported illicit drug use within the past month, and fewer than $3 \%$ reported pastmonth use of illicit drugs other than marijuana (NIDA 2015b). 
support for a policy does not guarantee that the policy will be advanced by a governing party or passed into law. ${ }^{7}$ Still, it is within the power of democratically elected governments to end prohibition, and its persistence results at least in part from its continued support among the electorate. Were ending the injustice of prohibition an important enough issue for enough voters, it would have greater political traction. Moreover, those jurisdictions that have liberalized their drug laws have largely done so as a result of political pressure from their citizens. Seven of the eight American jurisdictions that legalized recreational cannabis did so as the result of a majority vote on a ballot initiative (i.e. via plebiscite) $;^{8}$ the Canadian government's plans to legalize cannabis in the first half of 2018 would fulfil a promise made by the governing Liberal Party in the course of the 2015 election campaign; and, of course, the 1933 passage of the 21st Amendment to the US Constitution, which repealed the prohibition of alcohol, was the result of a 2/3rds majority vote of both Houses of Congress. ${ }^{9}$

Because the criminal law is under democratic control, the citizens of states that prohibit drugs - all of them, and not merely drug users - are in an important sense responsible for the harms that result from the drug trade. Those harms are the result of policies enacted by democratic institutions and so in principle expressing the considered views of the public. While the connection between majority policy preferences and the content of the law is far from straightforward, there is nevertheless an important sense in which ending prohibition is within the control of the American public; it simply requires repealing some criminal laws and passing some news ones, something that is entirely within the power of democratically elected governments who are responsive to the publics that elected them. That this is extremely unlikely reflects in part the fact that a significant proportion of the American public endorses the War on Drugs and the harms that it creates, and this tacit endorsement arguably makes that public complicit in the harms that prohibition generates.

This institutional responsibility, however, is much less clear in the

7 Thanks to an anonymous referee for urging me to discuss the relationship between majority preferences and policy changes in democratic contexts.

8 Alaska, California, Colorado, Maine, Massachusetts, Nevada, Oregon, Washington, and the District of Columbia all legalized marijuana through majority vote on a proposition appearing on the ballot. The sole exception thus far is Vermont, which did so via a bill introduced in the state legislature, rather than via ballot initiative.

9 It's worth noting, however, that the 21st Amendment is the only constitutional amendment to secure the required ratification by three fourths of the states through the use of one-off state conventions rather than by passage in state legislatures. It therefore stands alongside the use of ballot initiatives to legalize marijuana as an example of the ways in which majority policy preferences are not always easily secured through legislative means. 
example of sweatshop labor. Global economic institutions are not under the direct democratic control of the citizens any particular country: in fact, many such institutions often are not under any centralized control at all, and are certainly not constrained significantly by democratic control. Democratically elected governments can choose - at significant cost - to opt out of some of those institutions, but even if they do so those institutions continue to be in force and to wield significant power. So individual consumers in wealthy nations are far less responsible for the workings of those institutions.

Moreover, the political institutions of garment-producing nations like Bangladesh also bear some responsibility for lax labor standards and enforcement. That is not to say that there is nothing we can do, of course, but the enforcement of global labor standards is much less subject to democratic control than the content of domestic criminal law. While we cannot just change the global economic order by voting to do so, we can change the criminal laws of our state through straightforward democratic means, as was done in Portugal and several American states. Our ability to reduce the harms of the drug war through democratic means makes us more morally responsible for the persistence of those harms.

\subsection{Privilege}

We all have a reason not to consume unethically produced consumer goods. But just as we can satisfy this responsibility by purchasing fair trade and organic food and clothing, perhaps we can do the same with drugs: home-grown and ethically sourced marijuana, for example, would avoid many of the concerns raised above. I will return to this objection in Section 5.1, below. However, even if we concede the possibility of ethically sourced drugs, there is an additional moral reason to refrain from drug use that applies to many - though not all - drug users. The freedom to use illegal drugs without significant fear of criminal sanction is one expression of white middle-class privilege. Given the extreme racial disparity in the enforcement of drug laws, it is arguably among the more powerful forms such privilege can take.

White, middle-class, university-educated North Americans can typically purchase and consume illicit drugs safe in the knowledge that it is very unlikely that they will be stopped by police, searched, arrested, charged, or convicted. African-Americans, however, are more than four times as likely as white Americans to be arrested for drugs, despite using 
drugs at roughly the same rates (Mitchell and Caudy 2015). ${ }^{10}$ A drug charge also has the potential to be much more costly for a low-income American than a middle-class one; the loss of public housing, welfare, or food stamps is a non-issue for white professional home-owning drug users, but is a significant risk for low-income drug users. That African-Americans are more likely than white Americans to be poor compounds the potential for injustice, as they are more likely to be arrested for drug crimes, and more likely to suffer significant hardship as a result of such an arrest. Not only are they much more likely to be arrested for drug use that affluent white drug users, but such arrests can easily make them homeless.

The ability to violate the law and use drugs involves much less risk for some citizens than for others. This inequitable treatment is unfair, and is directly generated by prohibition. As with the harms of drug production, the main way of ending the unfair privilege in drugs is by repealing prohibition. Nonetheless, while the unfairness exists, the exercise of such privilege is something those who have it have a moral reason to avoid.

At the very least, those who use drugs recreationally and who have the privilege to do so without significant fear of sanction ought to both endorse and actively work toward the end of prohibition. Drug users who do not take a public stance in favor of ending prohibition show themselves to be willing to accept a privileged de facto immunity that they are unwilling to extend to others. They therefore treat the interests of others as less deserving of concern than their own. This powerful and morally objectionable form of hypocrisy is on display any time someone is willing to blithely break the law and yet not object to - or, worse, actively endorse - the prosecution of others who break the same laws. ${ }^{11}$ This hypocrisy would be objectionable even in the absence of racial bias in the enforcement of drug laws. Given the existence of such bias, those who are privileged enough to be largely free from fear of drug-related arrest or prosecution should refrain from the use of illegal drugs.

\section{THE PARADOX OF DRUG LAWS}

Thus far I've made two distinct arguments. First, existing drug laws are unjust. Second, illegal drug use is unethical. These two arguments appear to be in tension, since it seems that I am arguing that both drug prohibition

10 More precisely, African-Americans of 25 and under are somewhat less likely than whites to use drugs, while those 26 and older are somewhat more likely to use drugs; this is sometimes called the "racial age crossover effect" (Mitchell and Caudy 2015).

11 R. Jay Wallace offers an account of the moral blameworthiness of hypocrisy along these lines in (Wallace 2010) 
and drug use are unjust. But, one might think, if laws banning drugs are unjust, then shouldn't we conclude that there's in fact nothing immoral about drug use?

One straightforward way of resolving this tension would be to appeal to the existence of a general moral obligation to obey the law in a just state, even in cases where we believe the law to be unjust. John Rawls, for example, argues that, provided the injustice does not exceed certain limits, in just states we "normally have a duty to comply with unjust laws in virtue of our duty to support a just constitution." (1971:311). There are several arguments for such an obligation, drawing on the tacit consent of those subject to the law (Locke 1988), the importance of general obedience in securing the many valuable benefits of a just state (Wellman 2001), or principles of fairness and the unfairness of free-riding within generally just social institutions (Rawls 1999). As Rawls puts this point, provided that "the constitution is just and that we have accepted and plan to continue to accept its benefits, we have both an obligation and a natural duty... to comply with what the majority enacts even though it may be unjust". Justice, he argues, "binds us to a just constitution and to the unjust laws which may be enacted under it" (1999: 180).

However, many theorists reject the idea that there is a general obligation to obey the laws of a just state (e.g. Wolff 1970, Raz 1984, Simmons 2001). We may have strong moral reasons to conform with just laws, but this does not mean that the law itself gives us any such reasons. Rather, the law, when it is just, tracks what we have independent moral reason to do. When those reasons exist, we should do what the law requires, but not for the reason that the law requires it. And when no such independent reasons exist, the law typically does not create one, particularly when there are independent moral reasons not to comply with the law. As Joseph Raz puts it, the purported moral obligation to obey the law "is at best redundant" (1984: 140). 'At best,' because it would only make a difference when there are no independent reasons to do what the law commands, and so, if taken seriously, could easily lead people to act in ways that are unjust.

This suggests two distinct perspectives on obedience to unjust laws. Either we have an obligation to obey them in virtue of their being laws, or else their injustice means that, since we have no independent reason to do what they require, we have no obligation to obey them. However, the case of unjust drug laws represents an interesting exception to this general way of carving up the conceptual terrain. Because the drug laws are unjust, there are no independent reasons justifying those laws that explain why we ought to obey them. Nonetheless, the existence of the drug laws creates a strong moral reason not to use drugs, a reason that is entirely independent 
of any general moral obligation to obey the law.

To say that unjust laws create moral obligations to obey them might seem paradoxical without appeal to a general obligation to obey. However, this paradox is only apparent. Existing drug laws are unjust because they impose significant harms on many vulnerable people, and these harms could be greatly reduced by ending prohibition. These same reasons explain why illegal drug use is unethical. That is, the production and distribution of drugs is so harmful precisely because it is illegal, and these very same harms explain why consuming drugs is unethical. Drug laws both create the conditions for violence and exploitation, and make possible the kind of systematically racist enforcement that makes recreational drug use by privileged individuals morally troubling. In both cases, then, the reason that drug use is unethical is because of the existence of laws prohibiting drugs.

So while prohibition makes it unethical to consume drugs, the mere fact that drug use is against the law does not carry any moral weight at all. Rather, it is the unjust conditions created by the existence of the laws, and not the laws themselves, that make recreational drug use unethical, and these very same conditions explain why prohibition is unjust.

Those, like Raz, who reject the existence of a general obligation point out that a law is just if there are independent moral reasons to do what it commands. However, drug prohibition is an example of an unjust law that we have independent moral reasons not to violate. Of course, these reasons are independent only in the sense that it is not the existence of the law qua law that gives us a moral reason not to violate the law. In a different sense, the existence of the obligation is highly dependent on the existence of the law, since the law creates the conditions - violence, exploitation, and biased enforcement - that make the activity of drug use deeply ethically troubling. So while the claim that the injustice of the law creates the moral obligation to obey it sounds paradoxical, the paradox dissolves when we recognize that the injustice of the drug law does not explain the existence of the obligation to conform to it. Rather, both the injustice and the obligation are explained by the existence of the violence, exploitation, and discrimination that the law brings into being.

\section{OBJECTIONS AND REPLIES}

\subsection{Ethically sourced drugs}

The analogy between drugs and low-cost clothing suggests a possible defense of recreational drug use. The existence of unethical low-cost 
clothing is clearly not a reason to forego clothing altogether. Rather, it is a reason to purchase ethically sourced clothing, even if that clothing is more expensive. By the same token, the existence of unethically sourced drugs may not be a reason to avoid drugs altogether: instead, it simply gives drug users a strong reason to choose ethically sourced drugs. Homegrown organic marijuana, for example, seems to avoid concerns about the harmful and exploitative drug trade raised above.

There are two points to make in response to this suggestion. First, while it is true that ethically sourced drugs would certainly be better than unethically sourced ones, there simply are no ethical sources for many recreational drugs. Cocaine and heroin, for example, are not grown in North America or Europe, and as a result need to be smuggled from Asia and South and Central America. Drugs smuggled in this way are part of the violent and exploitative global trade, for which recreational users are in part responsible. Moreover, even drugs produced in North American and Europe - such as marijuana and synthetic drugs like MDMA and crystal methamphetamine - are often produced and distributed by the same violent and exploitative criminal organizations that distribute cocaine and heroin, and the people who produce them are not protected by labor laws. While marijuana and many synthetic drugs might, in principle, be ethically sourced by discreet small-scale producers who treat their employees well and who avoid violence, users who buy such drugs will typically have no way of knowing where their drugs come from, and so no way of knowing whether it is linked to such violent and exploitative drug markets.

Second, while those who grow their own organic marijuana or produce their own synthetic drugs strictly for personal use can avoid being implicated in many of the harms of the drug trade, they may nonetheless participate in the unethical exercise of privilege. While the exploitative source of most drugs is a reason to avoid them, so too are the unequal and unjust ways in which prohibition affects underprivileged groups. In fact, even the ability to produce one's own drugs without fear of detection can require access to space and privacy that members of underprivileged groups often lack: a homeowner can more easily produce drugs at home than a renter, for example.

One thing this argument suggests is that members of vulnerable and underprivileged groups who consume ethically sourced drugs do not behave immorally, since their drug use is not an example of unethical privilege. That is consistent with the argument advanced above, which does not depend on the claim that there is anything about drug use itself that is immoral. It is the nature of the drug trade and the privilege implicit 
in much illicit drug use that makes it morally objectionable. Illegal drug use that avoids both of these objections might not be open to moral censure. However, the vast majority of recreational drug use does not fall into this category.

\subsection{Civil disobedience}

Civil disobedience is a powerful way of protesting unjust laws, and one that is endorsed even by those, like Rawls, who defend the general obligation to obey the law. Since prohibition is unjust, drug use is arguably a form of protest against that injustice, and so counts as an instance of civil disobedience.

While civil disobedience is a morally admirable way of seeking to overturn unjust laws, it does not work as a defense of recreational drug use. First, drugs purchased to be used for the purposes of civil disobedience would still be unethically sourced, and so users remain implicated in the harms of the drug trade. Second, and more importantly, typical private recreational drug use does not count as an example of civil disobedience, which requires publicly breaking the law, doing so with the aim of communicating a political message or bringing about a change in the law, and willingly accepting the accompanying punishment (Rawls 1971, Brownlee 2004). Perhaps taking drugs in full view of the police at a public anti-prohibition rally counts as an instance of civil disobedience, and so of morally permissible drug use. Typical recreational drug use, however, does not.

\subsection{Medical uses of drugs}

Many people use drugs for a range of health-related reasons, so another objection is that my argument unfairly blames people for using medicines for which they have a legitimate need. This includes drug use by addicts, but also includes other uses: people self-medicate with a variety of drugs to treat chronic pain, nausea, anxiety and depression, to combat the side effects of prescription medication, and for a range of other non-recreational reasons.

I accept that the medical use of drugs is different in important ways. It would indeed be unfair to blame those with a legitimate medical need for drugs for using them, including addicts, particularly when such users are not responsible for the ban on drugs and are in fact among those most affected by that ban. My argument addresses the recreational use of drugs for the sake of the pleasure they deliver. In fact, a recognition of the difference between medical and recreational uses is at the heart of one of the main exceptions to prohibition: the legal regulation of medical marijuana in many jurisdictions. Such programs generally provide users with both legal protection from prosecution and an ethical source for 
marijuana. A similar recognition justifies the common practice of prescribing methadone - otherwise an illegal drug - to opiate addicts. Again, this practice provides addicts with both legal protection and an ethically sourced product, while also addressing the health costs of drug use.

However, not every person who uses illegal drugs for medical reasons uses marijuana or opiates, or even has access to legal medical marijuana or methadone. Those who have a legitimate medical need for drugs but do not have access to a legally sanctioned supply do indeed use drugs that are produced in unethical ways. In their case the blame more properly falls on the law-makers who are responsible for depriving people of medically necessary drugs, rather than on those who have the need for those drugs. Recreational users lacking a legitimate medical reason for drug use, however, remain blameworthy for the unethical use of illegal drugs.

\subsection{Drugs may continue to be unethical even if drugs were legalized}

While the illegal drug trade is violent and exploitative, this does not mean that the legal trade in drugs would be an ethical one. After all, many perfectly legal consumer products are unethical, from cheap sweat-shop produced clothing and electronics to so-called conflict diamonds. Legalization is no panacea. While it might make it possible to provide ethical sources of marijuana and many synthetic drugs, drugs like cocaine and heroin would continue to be produced in the developing world by lowwage workers, and such workers would likely remain vulnerable targets of exploitation. At best, legalization might make possible a market for (perhaps more expensive) ethical drugs, but it would almost certainly not do away with unethically produced drugs. The realities of production and distribution in even a legal drug trade might mean that many drugs would continue to be unethical.

It is certainly true that legalization would not instantly make drug use ethical, and that many drugs might continue to be unethically produced and distributed even if prohibition were repealed. However, this is consistent with the argument advanced above: recall that it is not the mere illegality of drugs that makes them unethical, but the conditions created by that prohibition. To the extent that those conditions remained in place after prohibition was lifted, the argument would remain in force. Prohibition would make it possible for recreational drug use to be ethical, but it certainly would not guarantee it. But even if most drugs continued to be produced and distributed by vulnerable exploited workers, legalization would likely secure some degree of improvement in their working conditions, simply by making legal oversight and regulation possible, and by reducing the incentives for violence. Such improvements might not be 
enough to make drug use ethically unproblematic, but they could nonetheless be significant.

\subsection{Prohibition is justified}

I have argued that drug prohibition is unjustified, in large part because of the enormous social costs that it imposes. But perhaps this is a mistake. For example, perhaps the costs of prohibition - in lives lost, workers exploited, rights sacrificed, and people incarcerated - are worth it to keep drugs out of the hands of children, to secure an overall reduction in drug use, or to convey society's profound disapproval of drugs. ${ }^{12}$ Or perhaps the problem with the drug war is in the execution, not in the general approach. The current heavily punitive approach to drug crime may be ill conceived and enforced in a discriminatory manner, but this does not necessarily show that prohibition itself is unjust. Rather, it might show that prohibition ought to be pursued in less harmful and discriminatory ways. For example, justice might require reforming policing practices, eliminating mandatory minimum sentences for non-violent drug offences, or diverting those who commit such offences into alternatives to the prison system. While prohibition is enforced in discriminatory ways, the problem may not be prohibition so much as racism; after all, even perfectly just laws can be unjustly enforced. African-American drivers are much more likely to be stopped and searched than white drivers (LaFraniere and Lehren 2015) - a phenomenon known as 'driving while Black' - but that does not mean that traffic laws are unjust. Rather, it simply means that they are often enforced in a discriminatory way.

It may be that, were drugs not currently illegal, it would be unjust to introduce prohibition. But it may be a distinct question whether we ought to repeal prohibition, given that it is place. After all, even if we would have been better off had drugs never been prohibited, repealing prohibition might still make things worse. Many of those involved in the illegal drug trade would not transition directly into the legal drug trade, which could draw from a larger labour pool and which would have less need for smugglers and enforcers. So an end to prohibition might well leave many criminals unemployed and without their main source of income, and such criminals might respond by turning to other crimes, thus making crime worse (Rios 2012). Perhaps this is not relevant to the justification of prohibition, since some would argue that incarcerating people for

12 Peter de Marneffe argues that the prohibition of heroin is justified in order to secure an overall reduction in harm, and in particular to protect children, though he agrees with Husak that most other drugs should be legalized (de Marneffe 2005). See also (Bean 2008: 262-266). 
recreational drug use is necessarily unjust, regardless of whether repealing prohibition would lead to an increase in harms. But lawmakers interested in adopting policies that reduce the harms of drugs might justifiably choose to continue with prohibition even if they recognize that it is an imperfect policy that would not be implemented if it were not already in place (Wolff 2011: 78).

Whether prohibition is ultimately justified, however, does not affect the argument that illegal recreational drug use is unethical. If it turns out that the laws prohibiting the use of drugs are just, then that of course is a reason to follow them, since we have a moral reason to comply with laws that are just. My argument shows that we have moral reasons not to violate the drug laws even if they turn out to be unjust, and this is perfectly consistent with insisting that prohibition is just and that, as a result, drug use is unethical.

My argument would, however, lose some of its paradoxical appeal if it were true that drugs prohibition is ultimately justified. I have argued that prohibition makes the drug trade harmful and exploitative, and so makes drug use unethical. If it turned out that ending prohibition would not reduce the misery associated with the drug trade, then arguably prohibition itself would turn out not to create the conditions that makes drug use unethical. But this would be because those harmful conditions would continue to obtain in the absence of prohibition, and my argument is that it is the harmful conditions in which drugs are produced and distributed, and not the mere fact that they are illegal, that makes drug use unethical. Regardless of whether prohibition is just, then, the use of prohibited drugs remains unethical.

\section{6: Drinking alcohol during prohibition}

There is a clear and oft-noted analogy between the current prohibition of drugs and the prohibition of alcohol in the United States between 1920 and 1933. One potential objection to my argument, then, is that it would strongly suggest that drinking during prohibition was immoral, even though prohibition itself is now widely recognized as a mistake and the moderate consumption of alcohol is morally unobjectionable.

It's worth noting that drinking was not illegal during prohibition, as the 18th Amendment and the Volstead Act outlawed the production, distribution, and sale of alcohol, but not possession and consumption. So to the extent that the argument in this paper addresses the ethics of illegal drug use, it may not apply at all to drinking during prohibition.

Moreover, the alcohol example could only serve as an objection to the 
argument that illegal drug use is unethical if it were obviously true that drinking during prohibition was morally licit, and that is far from certain. Some of the arguments offered in this paper also apply to drinking during prohibition, and so do show that such drinking may well have been unethical. In particular, both the violent and illegal black market and the exploitation of workers outside the protection of the law were moral problems that faced prohibition-era recreational drinkers who drank bootlegger-sourced alcohol. Those objections do not apply to the wealthy Americans who were able to rely on private reserves of alcohol stockpiled before the introduction of prohibition, but this legal and ethical access to alcohol was a privilege that was denied to the vast majority of Americans. So as with drug prohibition, the risks and harms of alcohol prohibition were far from equally distributed. In such a context continuing to drink while at the same time supporting prohibition arguably constituted an objectionable form of privileged hypocrisy.

Drinking in the absence of prohibition may well be entirely unobjectionable, but then so too would be many cases of recreational drug use. So our current attitudes toward the ethics of drinking and the error of alcohol prohibition are perhaps best understood as suggestive of what ethical drug laws would look like, rather than as an objection to the argument that drug use under prohibition is unethical.

\section{CONCLUSION}

Existing drug laws are unjust, and cause considerable harm; we should work to overturn them. One might therefore be inclined to conclude that such laws do not deserve our respect, and so that we are free to violate them. This, however, would be a mistake. The ban on drugs may be unjust, but while they are banned it is immoral use them. Drug use is immoral because of the conditions created by the law, rather than because of the law itself. The very facts that give us a strong moral reason to conform to the law therefore also give us reason to overturn it.

\section{BIBLIOGRAPHY}

Alexander, M., 2010: The New Jim Crow: Mass Incarceration in the Age of Colorblindness, New York: New Press. Bean, P., 2008: Drugs and Crime 3rd Ed. Portland: Willan Publishing.

Brownlee, K., 2004: "Features of a Paradigm Case of Civil Disobedience", Res Publica 10: 337-351. 
Carson, E and Anderson, E., 2016: “Prisons in 2015”, Bureau of Justice Statistics URL $=<$ https://www.bjs.gov/content/pub/pdf/p15.pdf.> Accessed May 6, 2017.

Cave, D., 2012: "Mexico Updates Death Toll in Drug War to 47,515, but Critics Dispute the Data", New York Times, Jan 11, 2012, URL=<http://www.nytimes.com/2012/01/12/ world/americas/mexico-updates-drug-war-death-toll-but-critics-dispute-data. html? r=1\&>. Accessed May 6, 2017

Degenhardt, L. et al., 2008: "Toward a Global View of Alcohol, Tobacco, Cannabis, and Cocaine Use: Findings from the WHO World Mental Health Surveys", PLOS Medicine: 5 (7): 1053-1067.

de Marneffe, P., 2005: “Against Drug Legalization”, in The Legalization of Drugs: For and Against, ed. D. Husak and P. de Marneffe, Cambridge: Cambridge University Press.

Drucker, E., 1999: "Drug Prohibition and Public Health: 25 Years of Evidence”, Public Health Reports 114: 14-29.

Health Canada, 2015: “Canadian Tobacco Alcohol and Drugs Survey”, URL=<https:// www.canada.ca/en/health-canada/services/canadian-tobacco-alcohol-drugssurvey/2015-supplementary-tables.html\#all> Accessed May 6, 2017.

Husak, Douglas , 2002: Legalize This! The Case for Decriminalizing Drugs, London: Verso.

— 2005: "For Drug Legalization", in The Legalization of Drugs: For and Against, ed. in Douglas Husak and Peter de Marneffe, Cambridge: Cambridge University Press.

Kaeble Danielle, and Bonczar, Thomas. 2016: "Probation and Parole in the United States, 2015", Bureau of Justice Statistics. URL $=<$ https://www.bjs.gov/content/ pub/pdf/ppus15.pdf> Accessed May 6, 2017.

LaFraniere, S. and Lehren, A., 2015: "The disproportionate risks of driving while black", New York Times Oct. 24, 2015. URL=< https://www.nytimes.com/2015/10/25/us/ racial-disparity-traffic-stops-driving-black.html.> Accessed May 6, 2017.

Levitt, S. and Venkatesh, S. A., 2000: "An economic analysis of a drug selling gang's finances”, Quarterly Journal of Economics 115: 755-789.

Locke, J., 1988 [1689]: Two Treatises of Government, Cambridge: Cambridge University Press.

Mitchell, O and Caudy, M., 2015: "Examining racial disparities in drug arrests", Justice Quarterly 32: 288-313.

NIDA, 2015a: "National Survey of Drug Use and Health", National Institute on Drug Abuse, National Institutes of Health. URL $=<$ https://www.drugabuse.gov/nationalsurvey-drug-use-health >. Accessed June 2, 2017.

-2015b: "Nationwide Trends", National Institute on Drug Abuse, National Institutes of Health. URL $=<$ https://www.drugabuse.gov/publications/drugfacts/nationwidetrends $>$. Accessed May 6, 2017.

Pfaff, J., 2017: Locked In: The True Causes of Mass Incarceration - and How to Achieve Real Reform, New York: Basic Books.

Rawls, J., 1971 (2nd ed 1999): A Theory of Justice, Cambridge: Harvard University Press

- 1999: “The Justification of Civil Disobedience", in John Rawls: Collected Papers, ed. Samuel Freeman, Cambridge: Harvard University Press.

Raz, J., 1984: “The Obligation to Obey: Revision and Tradition”, Notre Dame Journal of Law, Ethics, and Public Policy 1: 139-155.

Rios, V., 2013: "Why did Mexico become so violent? A self-reinforcing violent equilibrium caused by competition and enforcement", Trends in Organized Crime 16: 138-155. 
- 2012: "Drug Legalization Could Create More Crime", New York Times, May 30, 2012. URL $=<$ http://www.nytimes.com/roomfordebate/2012/05/30/should-latinamerica-end-the-war-on-drugs/drug-legalization-could-create-more-crime > Accessed May 6, 2017.

Rotermann, M and Langlois, K., 2015: "Prevalence and correlates of marijuana use in Canada, 2012", Statistics Canada Health Reports, 26: 10-15.

Simmons, J., 2001: “Philosophical Anarchism”, in Justification and Legitimacy: Essays on Rights and Obligations, Cambridge: Cambridge University Press: 102-121.

Taxy, S., et al., 2015: "Drug Offenders in Federal Prison: Estimates of Characteristics Based on Linked Data”, Bureau of Justice Statistics. URL $=<\underline{\text { https://www.bjs.gov/ }}$ content/pub/pdf/dofp12.pdf .> Accessed May 6, 2017.

Vuolo, M., 2013: "National-level drug policy and young people's illicit drug use: A multilevel analysis of the European Union”, Drug \& Alcohol Dependence 131: 149 - 156.

Wagner, P. and Walsh, A., 2016: "States of Incarceration: The Global Context 2016", Prison Policy Initiative. URL=<https://www.prisonpolicy.org/global/2016.html $>$. Accessed June 7, 2017.

Wallace, R.J., 2010: "Hypocrisy, Moral Address, and the Equal Standing of Persons", Philosophy and Public Affairs 38: 307-341.

Wellman, C., 2001: “Toward a Liberal Theory of Political Obligation”, Ethics 111: 735759.

Werb, D. et al. 2011: "Effect of Drug-Law Enforcement on Drug-Related Violence: Evidence From a Systematic Review", International Journal of Drug Policy 22: 87-94.

Wolff, J., 2011: Ethics and Public Policy, Oxford: Routledge.

Wolff, R.P., 1970: In Defense of Anarchism, Berkeley, CA: University of California Press. 